\title{
Social Aspects of Cancer
}

National Cancer Institute

\section{Source}

National Cancer Institute. Social Aspects of Cancer. NCI Thesaurus. Code C15891.

Influence of social factors, such as community, policy, and legislation on cancer control and outcomes 